\title{
Realizing the Internet of NanoThings:-A Review
}

Dr.Brijesh Khandelwal ${ }^{1}$, Ashutosh choudhary ${ }^{2}$, Ankit Mishra ${ }^{3}$
${ }^{1}$ Associate Professor, Amity School of Engineering \& Technolgy, Amity University Chhattisgarh, Raipur, bbrijeshlko@yahoo.com

${ }^{2}$ Assistant Professor, Amity School of Engineering \& Technolgy, Amity University Chhattisgarh, Raipur, ashutoshchoudhary23@gmail.com

${ }^{3}$ Assistant Professor, Amity School of Engineering \& Technolgy, Amity University Chhattisgarh, Raipur, ankitmishra004@gmail.com

\section{Abstract:}

Nanotechnology is the science and technology in which thesize of devices and gadgets are in nanometers which ranges from 1 to 100 nanometers. The basic definition of Nanotechnology is "Nanotechnology is the engineering of efficient organization of devices at the molecular scale". In this paper we are discussing, "Nanotechnology and Internet of Nano Things(IoNT)".Nanotechnology may have the ablility to create variousnew materials and gadgets with an enormous scope of applications, such as nanomedicine, nanoelectronics, energy generation using biomaterials and end user products. The paper provides comprehensive review of Internet of Nano Things (IoNT) along with its architecture and focusing on the technologies and methodologies used in development of IoNT.

Keywords:Nanotechnology,Nano sensors, Internet of Things(IoT), Internet of Nano Things(IoNT), Internet of Multimedia Nano-Things (IoMNT)

\section{INTRODUCTION}

Nanotechnology is the science and technology in which the size of devices and gadgets are in nanometers which ranges from 1 to 100 nanometers. The basic definition of Nanotechnology is "Nanotechnology is the engineering of efficient organization of devices at the molecular scale". Originally , "Nanotechnology" is the projected capability to develop objects using bottom up approach, with techniques and devices being developed nowadays to make complete, high performance effective products[2].Nanotechnology may have the ability to create various new materials and gadgets with an enormous scope of applications, such as nanomedicine, nanoelectronics, energy generation using biomaterials and end user products. Nanotechnology not exclusively allows making some high-quality products requiring little to no effort and at minimal cost, but alsoallows creating new nanofactories at a similar minimal effort and at a faster speed. This exceptional capability to repeat its own particular methods for production is the reason why nanotech is said to be an exponential innovation. Nanotechnology has many applications in various fields like military, health and medicine, electronics, energy, social insurance, condition security etc. The "Internet of Things (IoT)" is interconnection of computing devices, automated and digital machines, things, sensors that are assigned with unique IP addresses having the ability to exchange information through a network without the need of human-tohuman or human-to-computer interaction. lot devices utilize a wide range of networking protocols, network domains and applications. Thus ,IoT is becoming a part of our everyday aspect of life just like water, electricity, mobile, TV and most recently the Internet[6].The most essential backbone trailing Internet of Things (IoT) is the pervasive existence of broad range of objects or things like RFID (Radio 
Frequency Identification) tags, sensors, devices, mobile technology, NFC (Near Field Communication), Smart Phones, etc. having unique addressing schemes like IP address which allows them to interact and communicate amongst one another in accordance to achieve desired objectives[2].Poor security systems for IoT devices could provide an access points for cyber-attacks by allowing malicious individuals to re-program a device to remake it to malfunction. Likewise, the confidentiality of data accumulated by IoT gadgets that touch peoples life must be protected.[6].The pervasively arranged interconnection of multimedianano-devices with present communication networks and thus Internet refers to a novel communication standard which is further called as the Internet of Multimedia NanoThings (IoMNT). IoMNT is really a cyber- physical framework with plenty of utilizations in security and defence, biomedical, environmental and industrial fields etc [11].

\section{INTERNET OF NANO THINGS(IONT)}

The Internet of Nano Things (IoNT) refers to the interconnection of nano devices, nano sensors, countless nano machines with the existing communication networks via Internet which has led to the advancement of next generation standard based on IoT. As per the current factual statistical reports by specialists, IoNT market is expected to develop from $\$ 4.26$ billion in 2016 to $\$ 9.69$ billion by 2020 at a normal Compound Annual Development Rate (CAGR) of 22.81\% from 2016 to 2020. A fraction of the important players in the advertisement of IoNT are Intel Enterprise, Cisco Systems Inc., Qualcomm Incorporated, Juniper Networks and IBM Corporation in U.S., Schneider Electric and Alcatel-Lucent S.A. in France and many others[4].The framework for Internet of Nano Things (IoNT) can be deployed by integrating nano devices, nano sensors and several other technologies like IoT, Sensor Network, Cloud Computing, Big Data Analytics etc. The most complex and advanced procedures are utilized by IoNT for information gathering, which empowers IoNT to enlarge its base from existing applications to wide-ranging array of new and propelled applications when compared with IoT.. The Internet of Nanothings (IoNT) along with wireless area networks has led to the evolution of a new concept known as Internet of Everything(IoE).

\section{A. NETWORK ARCHITECTURE OF IONT}

1. Nano-Nodes: The simplest and smallest nanomachines which can perform various computational tasks. As they have limited memory and transmits data over short distances. They might be deployed in human body or in any physical things such as pens, books, keys, doors etc.

2. Nano-Routers: The Nano-Routers have higher computational assets than nano nodes. Since, they are located between then nonodes, they gather all the information which comes from different nano nodes. Nano- routers also monitors the nanonodes using control commands such as on/off, read value, sleep etc.

3. Nano-micro interface devices: These devices collects the information coming from different nanorouters and pass it on to the micro scale and vice versa. They are also called as hybrid devices as they can communicate both in nano scale as well as in micro scale.

4. Gateway: Gateway enables the remote control of entire nano system over the Internet . With the help of Gateways, doctors can access the information from Human body anytime and anywhere using Internet. 


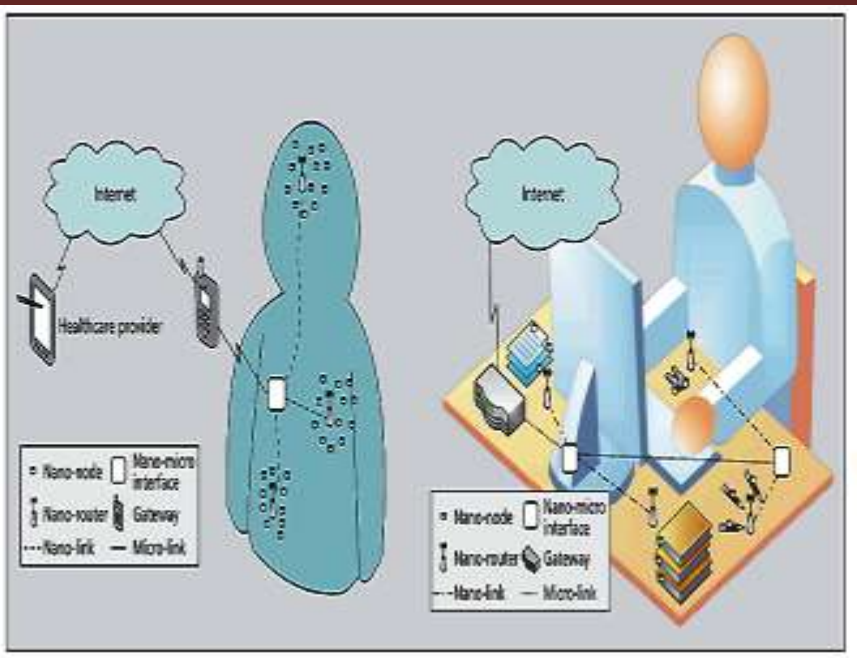

Fig 1: Network Architecture ofIoNT

\section{LITERATURE REVIEW}

Ian F. Akyildiz, Josep Miquel Jornet, "The Internet of Nano-Things".In this paper, the researchers focuses on electromagnetic communication in nanoscale devices by drawing attention towards channel modeling, information encoding and networking protocols for nano-devices based on IoNT. The Information and Communication society(ICT ) should provide some new solutions with regard to communication in nanoscale devices and nanonetworks [1].

AnandNayyar, VikramPuri, Dac-Nhuong Le (LêĐắcNhường), "Internet of Nano Things (IoNT): Next Evolutionary Step in Nanotechnology", Nanomachine is characterized as the fundamental useful unit incorporated by means of nano-components to perform essential tasks like detecting or inciting. Nano-machines can be additionally utilized as establishment for improvement of nano-bots, nano-processors, nano-clocks and nano-memory. Aside from dealing with examining on different application field and improvement of Nanotechnology based IoNTgadgets, new security and protection systems should be looked into concerning the information being gathered by nano sensors[2].

Karan Agarwal, Kunal Agarwal, Shalini Agarwal, "Evolution of Internet of Nano Things (IoNT)",With the increase in internet users, there is need for more bandwidth. This issue can be solved by using a frequency band called as Terahertz band. As it provides very large amount of channel capacity which makes massive bandwidth available for very short ranges (>1m) [3].

Kaushal Dabhi, Ashish Maheta, "Internet of Nano Things-The Next Big Thing",The in-detail view of Internet of Nano Things (IoNT)- Architecture, Application areas and Challenges has been proposed by authors in order to make researchers aware of IoNT standards and how to overcome existing challenges for future research in IoNT [2-4].

Hemdan Ezz El-Din, D. H. Manjaiah, "Internet of Nano Things and Industrial Internet of Things", In order to provide in-depth knowledge about Internet of Nano Things (IoNT) and Industrial Internet of Things(IIoT) technologies, the researchers provided various fundamental concepts, architecture, communication classifications, communication issues, applications,benefits, security and future research directions in [5]. 
Bassam Al-Shargabi, Omar Sabri, "Internet of Things: an Exploration Study of Opportunities and Challenges",IoT operational model based on how they are interconnected and operated, the Internet Architecture Board (IAB)classifies them into :IoT Device-to- Device model, IoT Device-toCloud model, IoT Device-to-Gateway Model, IoT Back-End-Sharing Data model. An explored analysis for the major opportunities and challenges faced in implementation of IoT technology was introduced [6].

Andrew Whitmore, Anurag Agarwal, Li Da Xu, "The Internet of Things-A survey of topics and trends". In this paper the present scenario of IoT, technologies supporting IoT, its applications and challenges, recent advances and development through an in-depth review has been presented. Theliterature was classified into six major categories: technology, applications, challenges, business models, future directionsand overview/survey [7].

Mahdi H. Miraz, Maaruf Ali, Peter S. Excell, Rich Picking, "A Review on Internet of Things (loT), Internet of Everything (IoE) and Internet ofNano Things (IoNT)" . TheInternet of Things (loT), Internet of Everything (loE) and Internet of Nano Things (loNT) are briefly studied and variousfuture applications of these technologieswas also presented by authors [8].

Najah Abu Ali, Mervat Abu-Elkheir, "Internet of Nano-Things Healthcare Applications: Requirements, Opportunities, and Challenges".The architectural requirements needed for IoNTbased healthcare applications and the networking requirements of those applications was identified. The implementation of IoNT and performance evaluation issues, such as deployment, communication with different networking standards was briefly analyzed. And finally the major challenges of integrating healthcare applications at the nanoscale with IoNT was presented [9].

Najah Abu Ali, WesamAleyadeh, MervatAbuElkhair, "Internet of Nano-Things Network Models and Medical Applications" . The researchers presented different network models of IoNT and the architectural requirements for implementing this technology in healthcare applications such as drug delivery and disease detection. The nano networks protocol stack was categorized into two main categories: Layer-based and non-layer based models. And finally a comparison between the two models along with the advantages anddisadvantages ofboth was provided[10].

Josep Miquel Jornet, Ian F. Akyildiz, “The Internet of Multimedia Nano-Things”,Josep Miquel Jornet et al. discusses the latest techniques used in the development of nano things and major research challenges in the recognition of the IoMNT. The future research trends and major challenges are defined in terms of multimedia data and signal processing, propagation modeling for communication amongst nanothingsin the terahertz band, physical layer solutions for terahertz band communication and protocols for the IoMNT. The researchers also proposed novel medium access control techniques, addressing schemes, neighbour discovery and routing mechanisms, a novel QoS-aware cross-layer communication module, and novel security solutions for the IoMNT [11].

Falko Dressler, Stefan Fischer, "Connecting in-body nano communication with body area networks: Challenges and opportunities of the Internet of Nano Things", the author examined the challenges and opportunities of connecting Body Area Networks and other outer gateways with inbody nano-devices. A novel network architecture supporting the application requirements was derived 
and in particular simulation-based performance evaluation and security issues was also been identified [12].

Table 1: The table shows various methodologies used in IoNT

\begin{tabular}{|c|c|c|c|c|}
\hline $\begin{array}{l}\text { S. } \\
\text { No }\end{array}$ & TITLE & AUTHOR & METHODOLOGY & REMARKS \\
\hline 1 & $\begin{array}{l}\text { Evolution of } \\
\text { Internet } \begin{array}{r}\text { of } \\
\text { Nano Things } \\
(\text { IoNT) }\end{array}\end{array}$ & $\begin{array}{l}\text { Karan Agarwal, } \\
\text { Kunal Agarwal, } \\
\text { ShaliniAgarwal }\end{array}$ & $\begin{array}{l}\text { Nanotechnology, } \\
\text { nodes, Nano routers, Nano- } \\
\text { micro interface devices }\end{array}$ & $\begin{array}{l}\text { In Internet of Nano Things } \\
\text { (IoNT), a large number of } \\
\text { nano machines like sensors, } \\
\text { nanodevices are } \\
\text { interconnected } \\
\text { communication networks } \\
\text { over the Internet and } \\
\text { totally change the way in } \\
\text { which devices are } \\
\text { connected together. But } \\
\text { integration of hardware and } \\
\text { software solutions to the } \\
\text { existing setup should be } \\
\text { implemented. }\end{array}$ \\
\hline 2 & $\begin{array}{l}\text { The Internet of } \\
\text { Nano-Things }\end{array}$ & $\begin{array}{l}\text { Ian F. Akyildiz, } \\
\text { Josep Miquel } \\
\text { Jorne }\end{array}$ & $\begin{array}{lrr}\text { Nano nodes, Nano routers, } \\
\text { Nano-micro } & \text { interface } \\
\text { devices, Gateway, } & \text { Medium } \\
\text { Access Control } & \text { (MAC) } \\
\text { protocols } & & \end{array}$ & $\begin{array}{l}\text { The } \\
\text { implementation } \\
\text { nanomachine, nano scale } \\
\text { networks and proposed } \\
\text { architecture should have } \\
\text { been performed. }\end{array}$ \\
\hline 3 & $\begin{array}{l}\text { Internet of } \\
\text { Nano Things } \\
\text { (IoNT):Next } \\
\text { Evolutionary } \\
\text { Step in } \\
\text { Nanotechnolog } \\
\text { y }\end{array}$ & $\begin{array}{l}\text { AnandNayyar, } \\
\text { VikramPuri, } \\
\text { Dac-NhuongLe }\end{array}$ & $\begin{array}{l}\text { Nanosensors, } \\
\text { machines, } \\
\text { Body Sensor Networks, Nano } \\
\text { Communication, Wireless } \\
\text { Networks }\end{array}$ & $\begin{array}{l}\text { Internet of Nanotechnology } \\
\text { emerging from the concept } \\
\text { of Internet of Things is the } \\
\text { forthcoming miniature nano } \\
\text { sensor networks and can be } \\
\text { adopted in real time } \\
\text { applications. But } \\
\text { compatibility of nano } \\
\text { sensors and nano networks } \\
\text { to hold large varieties of } \\
\text { data should be proposed } \\
\text { along with security. }\end{array}$ \\
\hline 4 & $\begin{array}{l}\text { The Internet of } \\
\text { Multimedia } \\
\text { Nano-Things }\end{array}$ & $\begin{array}{lr}\text { Josep } & \text { Miquel } \\
\text { Jornet, } & \text { Ian } \\
\text { F.Akyildiz } & \end{array}$ & $\begin{array}{l}\text { Novel medium access control } \\
\text { techniques, addressing } \\
\text { schemes, neighbor discovery } \\
\text { and routing mechanism, a } \\
\text { novel Qos-aware cross-layer } \\
\text { communication module and }\end{array}$ & $\begin{array}{l}\text { There are still limitations in } \\
\text { implementing the integrated } \\
\text { multimedia but we believe } \\
\text { that research on } \\
\text { communication-focused } \\
\text { investigations in hardware }\end{array}$ \\
\hline
\end{tabular}




\begin{tabular}{|c|c|c|c|c|}
\hline & & & $\begin{array}{l}\text { novel security for the IoMNT, } \\
\text { miniature photo detectors and } \\
\text { acoustic nano transducers, } \\
\text { terahertz band channel } \\
\text { modeling. }\end{array}$ & $\begin{array}{l}\text { will benefit from being } \\
\text { conducted in parallel from } \\
\text { an early stage. }\end{array}$ \\
\hline 5 & $\begin{array}{l}\text { Internet of } \\
\text { Nanothings- } \\
\text { The Next Big } \\
\text { Thing }\end{array}$ & $\begin{array}{l}\text { Kaushal Dabhi, } \\
\text { Ashish Maheta }\end{array}$ & $\begin{array}{l}\text { Nanomachines, nano sensors, } \\
\text { nano routers, nano-micro } \\
\text { interface gadgets }\end{array}$ & $\begin{array}{l}\text { Internet of Things is } \\
\text { reckoned as the most and } \\
\text { has the adequacy to be } \\
\text { endorsed in different fields. } \\
\text { But security and protection } \\
\text { instruments must be } \\
\text { conduced and proposal to } \\
\text { make nanosensors and } \\
\text { nanosystems to hold large } \\
\text { data must be initiated upon. }\end{array}$ \\
\hline 6 & $\begin{array}{l}\text { Internet of } \\
\text { Nano-Things } \\
\text { Healthcare } \\
\text { Applications: } \\
\text { Requirements, } \\
\text { Opportunities, } \\
\text { and Challenges }\end{array}$ & $\begin{array}{l}\text { Najah Abu Ali, } \\
\text { Mervat Abu- } \\
\text { Elkheir }\end{array}$ & $\begin{array}{l}\text { Nanorouters, Nanointerfaces, } \\
\text { Nanomachines, IoT, IoNT, } \\
\text { Ultrasonic communication, } \\
\text { design of 3D tissue models, } \\
\text { Pulse-based communication } \\
\text { protocols, routing protocol } \\
\text { based on selective } \\
\text { forwarding, nanosensor, } \\
\text { Nano-Sim, Nanosensor- } \\
\text { integrated textiles, . Off-body } \\
\text { networks, On-body networks, } \\
\text { intra-body networks }\end{array}$ & $\begin{array}{l}\text { Architectural requirements } \\
\text { and network requirements } \\
\text { necessary for IoNT-based } \\
\text { healthcare applications are } \\
\text { identified. Challenges of } \\
\text { realizing healthcare } \\
\text { applications at the } \\
\text { nanoscale in each of the } \\
\text { networking layers is } \\
\text { outlined but no proper } \\
\text { solution to totally cope up } \\
\text { with it is given. }\end{array}$ \\
\hline
\end{tabular}

\section{CONCLUSION}

Internet of Nano Things (IoNT) is the next futuristic techno-scientific revolution and the products resulting from it will highly influence all the dimension of our economy and style of living. Since, Nanotechnology is highly interdisciplinary, which involves physics, chemistry, biology, electrical engineering, chemical engineering and material science, thus transforming the entire range of the engineering disciplines. In near future the advanced development of Nanotechnologies, Nano machines, Internet of Things (IoT) and Internet of Nano Things (IoNT) will have a huge impact on almost every field of science and engineering which would be ultimately beneficial for the whole world. The paper provides comprehensive review of Internet of Nano Things (IoNT) along with its architecture and focusing on the technologies and methodologies used in development of IoNT. In near future IoNT based devices along with hardware and software solution will be provided by researchers.

\section{REFERENCES}

I. Ian F. Akyildiz, Josep Miquel Jornet, "The Internet of Nano-Things ”, IEEE Wireless Communications 2010, 1536-1284/10 
II. AnandNayyar, VikramPuri, Dac-Nhuong Le (LêĐắcNhường), "Internet of Nano Things (IoNT): Next Evolutionary Step in Nanotechnology", Nanoscience and Nanotechnology 2017, 7(1): 4-8, DOI: 10.5923/j.nn.20170701.02

III. Karan Agarwal, Kunal Agarwal, Shalini Agarwal, "Evolution of Internet of Nano Things (IoNT)", International Journal of Engineering Technology Science and Research 2017, ISSN 2394 - 3386, Volume 4, Issue 7

IV. Kaushal Dabhi, Ashish Maheta, "Internet of Nano Things-The Next Big Thing", International Journal of Engineering Science and Computing, 2017, Volume 7, Issue No.4

V. Hemdan Ezz El-Din, D. H. Manjaiah, "Internet of Nano Things and Industrial Internet of Things", Internet of Things: Novel Advances and Envisioned Applications, https://doi.org/10.1007/978-3-319-53472-5_5

VI. Bassam Al-Shargabi, Omar Sabri, "Internet of Things: an Exploration Study of Opportunities and Challenges", ICEMIS2017, 978-1-5090-6778-7/17

VII. Andrew Whitmore, Anurag Agarwal, Li Da Xu, "The Internet of Things-A survey of topics and trends",InfSyst Front, DOI: 10.1007/s10796-014-9489-2

VIII. Mahdi H. Miraz, Maaruf Ali, Peter S. Excell, Rich Picking, "A Review on Internet of Things (loT), Internet of Everything (IoE) and Internet ofNano Things (IoNT)", Internet Technologies and Applications (ITA), 2015IEEE, DOI: 10.1109/ITechA.2015.7317398

IX. Najah Abu Ali, Mervat Abu-Elkheir, "Internet of Nano-Things Healthcare Applications: Requirements, Opportunities, and Challenges",The First International Workshop on Advances in Body-Centric Wireless Communications and Networks and Their Applications 2015, 978-14673-7701-0/15

X. Najah Abu Ali, WesamAleyadeh, MervatAbuElkhair, "Internet of Nano-Things Network Models and Medical Applications", 978-1-5090-0304-4/16, 2016 IEEE

XI. Josep Miquel Jornet , Ian F. Akyildiz, "The Internet of Multimedia Nano-Things", Nano Communication Networks 3 (2012) 242-251, 1878-7789, doi:10.1016/j.nancom.2012.10.001

XII. Falko Dressler, Stefan Fischer, "Connecting in-body nano communication with body area networks: Challenges and opportunities of the Internet of Nano Things", Nano Communication Networks, 2015, http://dx.doi.org/10.1016/j.nancom.2015.01.006 1878-7789 